\title{
CONNECTIVITY OF QUALITY MANAGEMENT SYSTEMS AND ENVIRONMENTAL MANAGEMENT SYSTEMS
}

\author{
Miroslav Rusko, Iveta Pavlova, Jaromira Vanova \& Ruzena Kralikova
}
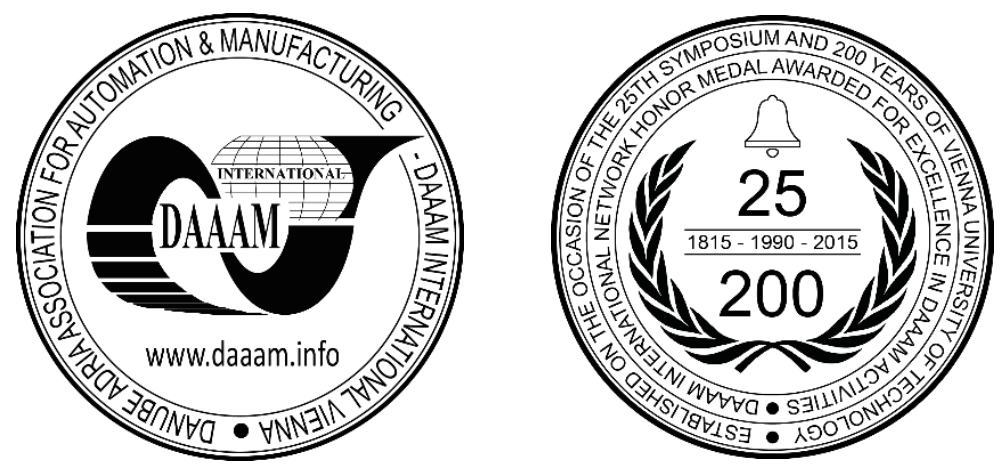

This Publication has to be referred as: Rusko, M[iroslav]; Paulova, I[veta]; Vanova, J[aromira] \& Kralikova, R[uzena] (2017). Connectivity of Quality Management Systems and Environmental Management Systems, Proceedings of the 28th DAAAM International Symposium, pp.1213-1220, B. Katalinic (Ed.), Published by DAAAM International, ISBN 9783-902734-11-2, ISSN 1726-9679, Vienna, Austria

DOI: $10.2507 / 28$ th.daaam.proceedings.169

\begin{abstract}
Environmental management is a set of voluntary environmental policies allowing the introduction of a systematic approach for organizations in solving environmental issues. Economic, social and environmental situation in the last century has resulted in the activities represented by the concept of sustainable development In order for development to have a long-term positive effect, it must be sustainable. Sustainable development is about ensuring that the resources of the Earth, which we use to promote economic growth, will be available also to future generations. The attention that is currently paid to the threats posed by global climate change is an example of how human freedom and human development can be undermined when the interests of economic growth and development are separated from the interests of the environment. The current environmental problems' solution is not just a question of technical solution, which until recently was caused by either a response to an environmental problem accrued or within the more progressive approach as a preventive approach. It should be a change in the value of the orientation of a human, as an individual, but also of society and all mankind. As today's consumers are beginning to become increasingly more aware of the problems of environmental pollution, so do producers and trades are beginning to modify their thinking and behavior towards proenvironmental direction and this way try to address their consumers.
\end{abstract}

Keywords: Environment; development; sustainable development; product

\section{Introduction}

Excessive consumption of natural resources and reckless environment pollution are among significant global problems of our civilisation. The idea of infinite natural resources that can be used without limits as we wish, the idea that we can sustainably manage them on both global as well as regional level, the idea that the economic growth means progress, that science and technologies will solve all our existing and future problems is dominant with a part of the population. Contrarily, other part of the population radically refuses such approach to solving the current environmental problems. A solution is somewhere in between these two extremes. To contribute to sustainable development as regards not only the humanity but also all life forms on the planet means to reassess the system of our priorities. [8] 
It is necessary to limit the excessive polluting of the environment, reduce the population growth, in particular in developing countries, and to limit the excessive consumption in industrialized countries. Over-consumption in industrialized countries and under-consumption in developing countries (dialectically related to over-production and lagging-behind) is the main source of the global instability. [8] The current product policy sees a significant trend in focusing on a value-driven product strategy, i.e. a constant process of developing a product programme based on the value category for the customer. [7]

\section{Environmental management systems and quality management systems}

The requirements of the legislation in the area of environmental protection is continually tightening and their implementation requires ever greater demands on the security of the resources. To ensure compliance with individual legislation, however, does not guarantee a comprehensive and effective approach to environmental protection over the approach to the protection of the environment based on the system management approach. One of the ways to ensure a more effective and efficient approach to the protection of the environment in the company, to obtain a higher environmental credit and competitive advantage on the national and international market, is to introduce and certify an environmental management system according to the ISO 14001. EMS is the way of the implementation of environmental requirements, an indicator of competitiveness, a tool for fostering of environmental sustainability.

With the growing interest in maintaining and improving the quality of the environment, many organizations are turning with increased rate their attention to the potential environmental impacts of their activities. The interest in achieving and demonstrating of their good environmental performance through the management of the impacts of their activities, including the products and services, they consider the direction of their environmental policy and the objectives of development.

In the context of a tightening of the environmental laws for the development of economic policy, of the achievement of the objectives and priorities of the state environmental policy, of growing in the interests of the stakeholders in environmental issues, including sustainable development, as well as the increase of competitive performance, the organization is forced to reconsider its status and put in place an effective and efficient system the implementation of such, it reaches the meeting of these requirements.

EMS are applicable to the entire spectrum of organizations, from the productive of an industrial scale, in agriculture, in services, in the health sector and trade, in the region having regard to its local needs as well as conditions. An integral part of the building of the EMS is applying of such methods and procedures that allow, with their content and focus, on the basis of the latest findings from the fields of science, technology and engineering, to include a solution for alleviating and eliminating unwanted environmental impacts arising from the activities of the organization. The system affects the organisational structure, planning and control activities, resources, responsibilities, work practices, processes, and resources for the implementation of the environmental policy, objectives and ensuring the continuous improvement of care for the environment of the organization.

EMS is a voluntary instrument in the field of environmental management in an organization, introduced in order to achieve compliance with legal requirements. It includes organizational structure, planning, responsibilities, processes, proceedings and resources for preparing, implementing, reviewing and maintaining the environmental policy of the organization. It allows systematic management to achieve a level of performance that the organization has established by itself through the accepted policy of process and documentation within established environmental management system (EMS). EMS is a tool that brings together the approaches to the protection of the environment with the overall management of the organization in order to achieve environmental and business objectives of the management of the organization. It is applicable for any type of organization in industrial sector, in agriculture, in services, in the health sector and trade, in the financial sector or the public sector.

Slovakia's entry into the European Union has affected many changes in the business. For increasing competitiveness, there are created various tools for effective management of the organization and ensuring the quality of desired products outcomes in organizations. By increased demands and pressures from all stakeholders, we need to find a way how to react flexibly to their needs. Due to the trend of integration of management systems and to facilitate inerrability of individual management systems and for increasing the flexibility of management systems of enterprises, the Annex SL to Regulation ISO/EIC "Consolidated Supplement - Specific Procedures to ISO" was founded in 2012. According to this regulation, all standards for management systems that arise respectively will be revised after 2013 must have the same structure. All these aspects are reflected in the draft revision of ISO 9001:2015 and ISO 14001:2014. Organizations will have three years to be able to incorporate into their existing system the requirements and comprehensive approach defined in ISO 9001:2015 and ISO 14001:2014. From 2019, it will be necessary to fully comply with the requirements defined in these standards revisions. Availability of the draft ISO 9001:2015 and ISO 14001:2014 showed major shift in attitude and perception of quality and environment management. Some of the approaches are transferred from the requirements of the standard TS 16949 (automotive industry) or TQM models (EFQM excellence model).

The most important voluntary instrument of environmental care includes:

- environmental management systems,

- environmental assessment and labelling of products,

- green public procurement. [10] 
In terms of the most elaborated tools with high efficiency it is currently recommended in building and implementing the EMS the use of two standardized tools: EMAS III and ISO 14001: 2015. A system approach to environmental management can be by:

- EMS (Environmental Management Systems. Requirements with guidance for use) according to ISO 14001: 2015

- EMAS (Eco-Management and Audit Scheme) - EU Regulation 761/2001 of 19.3.2001 on the voluntary participation by organizations in a eco-management and audit scheme (EMAS II) amended the EC Regulation 1836/1993 (EMAS I) on the voluntary participation of industry at Community program of environmental management and assessment approved by the Council of Ministers EC 29.6.1993 (entered into force on 13.7.1993 with effect for individual Member States of the EU from 13.4.1995). It was subsequently amended by Regulation of the European Parliament and Council Regulation (EC) No. 1221/2009 on the voluntary participation by organizations in a Community eco-management and audit scheme - EMAS III. The SR was to promote EMAS, the Act NR SR. 351/2012 on environmental verification and registration of organizations in the EU Eco-Management and Audit Scheme and on amendments to certain laws.

- Voluntary tools of an environmentally oriented product policy can include tools standardised by:

$\circ \quad$ legal regulation (e.g. EMAS - legal regulation within the EU as well as SR)

- legal regulation and standard (e.g. type I environmental labelling - legal regulation within the EU as well as SR and ISO 14024)

○ standard (e.g. lifecycle assessment, standards of ISO 14040 series)

$\circ$ procedure specifying the certification conditions (e.g. PEFC), or the respective calculation (e.g. ecological, carbon or water footprint)

- $\quad$ non-standardised tools (e.g. environmental marketing, environmental benchmarking).[11]

Review of the EMS certification according to the ISO 14001 development of annual increase in organizations with a certified EMS in Slovak Republic are given in Table 1.

\begin{tabular}{|c|c|c|c|}
\hline Year & Number of certificates & Year & Number of certificates \\
\hline 1990 & 1 & 2006 & 103 \\
\hline 1996 & 1 & 2007 & 109 \\
\hline 1998 & 8 & 2008 & 170 \\
\hline 1999 & 13 & 2009 & 150 \\
\hline 2000 & 17 & 2010 & 118 \\
\hline 2001 & 23 & 2011 & 91 \\
\hline 2002 & 33 & 2012 & 59 \\
\hline 2003 & 41 & 2013 & 69 \\
\hline 2004 & 51 & 2014 & 94 \\
\hline 2005 & 77 & 2015 & 62 \\
\hline
\end{tabular}

Table 1. EMS certification in Slovak Republic

\section{Sustainable production and consumption}

The issue of sustainable consumption and Eco labelling was included into the agenda of a special meeting of the UN General Assembly - Earth Summit +5, the World Summit on Sustainable Development in Johannesburg, as well as into other important international activities. Poverty and environment degradation are closely interrelated. While poverty results in certain kinds of environmental stress, the major cause of the continued deterioration of the global environment is the unsustainable pattern of consumption and production, particularly in industrialised countries, which have serious consequences, aggravating poverty and imbalances. Measures to protect and improve the environment have to take into account the current imbalances in the global patterns of consumption and production. Development should include an effort to achieve sustainable consumption patterns.

At the same time, the society needs to develop effective ways of dealing with the problems of disposing of mounting levels of waste products and materials. Institutions should make a concerted effort necessary to reduce generation of wastes by:

- encouraging recycling in the industrial processes and at the consumed level;

- reducing wasteful packaging of products;

- encouraging the introduction of more environmentally sound products.[4]

Governments themselves play an important role as regards consumption, particularly in countries where the public sector plays a large role in the economy and can have a considerable influence on both corporate decisions and public perceptions. They should therefore review the purchasing policies of their agencies and departments so that they improve, where possible, the environmental content of government procurement policies, without prejudice to the international trade principles. An appeal for sustainable consumption was already made during the Earth Summit in Rio de Janeiro in 1992. Chapter 4 - "Changing Consumption Patterns" of the AGENDA 21 document concerns two programme areas: unsustainable patterns of production and consumption, and developing national policies and strategies to encourage 
changes in unsustainable consumption patterns. [4] Contrarily to the idea of sustainable development focusing in particular on the business area, sustainable consumption is a task especially for the consumers - individuals or the state. It is necessary for the consumers to change their purchase behaviour. However, they cannot do it just by themselves. Sometimes they lack information about how to live "more sustainably".

The European Parliament and the Council of the EU, having regard to the Treaty establishing the European Community, and in particular Article 175(3) thereof, stated that the Community's fifth environmental action programme (5EAP) "Towards Sustainability" ended on 31 December 2000 delivered a number of important improvements, and that continued effort is required to meet short-term and long-term environmental objectives as set out by EC.

The 6th EAP relates to a period of ten years $(2002-2012)$. The respective initiatives to meet long-term objectives in various policy areas consist of a whole series of measures, including legal regulations and strategic approaches. The document, besides other, states that a prudent use of natural resources and the protection of the global eco-system together with economic prosperity and a balanced social development are a condition for sustainable development. The 6th EU Environment Action Programme (6EAP) states that the consumers need information to help them chose more environmentally-friendly products with the aim of positively affecting the market. [13]

The 7th Environment Action Programme (EAP) will be guiding European environment policy until 2020.[1]

In order to give more long-term direction it sets out a vision beyond that, of where it wants the Union to be by 2050 : "In 2050, we live well, within the planet's ecological limits. Our prosperity and healthy environment stem from an innovative, circular economy where nothing is wasted and where natural resources are managed sustainably, and biodiversity is protected, valued and restored in ways that enhance our society's resilience. Our low-carbon growth has long been decoupled from resource use, setting the pace for a safe and sustainable global society."[2]

It identifies three key objectives:

- to protect, conserve and enhance the Union's natural capital

- to turn the Union into a resource-efficient, green, and competitive low-carbon economy

- to safeguard the Union's citizens from environment-related pressures and risks to health and wellbeing.

Four so called "enablers" will help Europe deliver on these goals:

- better implementation of legislation

- better information by improving the knowledge base

- more and wiser investment for environment and climate policy

- full integration of environmental requirements and considerations into other policies.

Two additional horizontal priority objectives complete the programme:

- to make the Union's cities more sustainable

- to help the Union address international environmental and climate challenges more effectively.

The programme entered into force in January 2014. It is now up to the EU institutions and the Member States to ensure it is implemented, and that priority objectives set out are met by 2020 .

\section{Environmentally business policy}

Business and industry, including international companies, play a decisive role in the social and economic development of a country. A stable political regime creates suitable conditions for business and industry, allowing to work responsibly and efficiently and to implement long-term strategies. Business and industrial activities are the foremost contributors to the prosperity growth, which is the main goal of development. Business companies - small and big, formal and informal - create the majority of working and business opportunities, as well as opportunities to make a livelihood. Suitable business and industrial policy and its practical implementation which makes use of more efficient production procedures, applies preventive strategies, uses cleaner technologies and processes in the whole life-cycle of a product and thus reduces generation of wastes, can help reduce the negative impact on the resources and the environment. Within the environment policy we can distinguish - regional environmental policy, environmental policy concerning investments, environmental policy concerning waste, product policy, environmentally oriented consumption policy and substance flow policy (see Figure 1).[9]

Management of some enterprises understood the context and introduced a system of responsible care and programmes of product stewardship which lead to openness and dialogue with employees and the public; they carry out environmental audit and evaluate fulfilment of individual programmes. A growing number of such management members voluntarily and at their own initiative take over the responsibility and manage their activities so as to minimise their impact on human health and the environment.

The situation was helped by regulation measures adopted by individual countries, such as higher awareness of consumers and the public, and awareness of the management in business and industry. A positive approach of business and industry to sustainable development can be increased by economic tools such as free-market mechanisms which allow 
for the product and service prices to reflect the environmental costs of their inputs, production, use, recycling and final disposal in a growing degree and in compliance with the specific conditions in individual countries.[4]

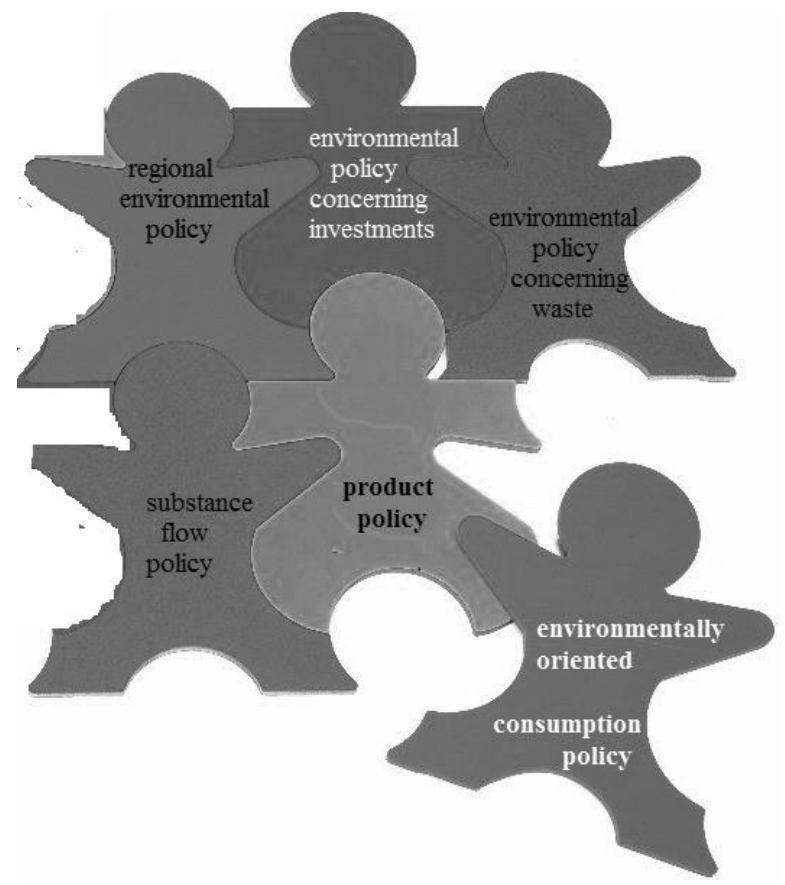

Fig. 1. Suitable business and industrial policy

Green purchasing is an example for the broad public and private sector, and it affects the market. Introduction of a policy of green public procurement increases the demand for environmentally sound products, which encourages the consumers of such products. Promotion of green public procurement gives incentives for development of industry, development of green technologies and products and promotes them on the market. Small and medium enterprise, in particular, can gain profit from green public procurement as it offers opportunities to find markets for their innovative solutions and products.

Green public procurement (GPP) is a way of integrating environmental requirements into the process of public procurement by public bodies through technical requirements or criteria for tender evaluation. The importance of green procurement is especially in the fact that it creates a market demand for the environmentally friendly products and thus promotes offer of these products. Introduction of an environmental point of view into public tenders can motivate producers to develop new products and technologies with less negative impacts on the environment as well as motivate suppliers to introduce environmental management systems. GPP is one of the set of efficient tools for promotion of production processes which are environmentally friendlier and stimulate supply of goods and services with the high value which is characteristic by its environmental benefit throughout the product's lifecycle. Follow the steps of a simple management model for systematic implementation of GPP in the organisation, Figure 2.

In October 2004 the first international conference of ecological sellers took place in the town of Sendai (Japan). More than 1,000 representatives gathered to confirm the importance of an ecological sale and joint international activities in the area. In the Sendai Declaration adopted at the conference, all stakeholders agreed upon establishment of an international organisation (International Green Purchasing Network - IGPN) with the main task of promoting ecological purchasing at global level. IGPN was established next year by various shareholders from international organisations, associations, government organisations, regional authorities and $\mathrm{NGO}$ and it took over the initiative to implement ecological purchasing.

IGPN collects and delivers information on global green purchasing activities, case studies on development of new eco-products and eco-services and know-how, purchasing guidelines, information on products, research outcomes and the latest trends, as well as on international conferences and workshops focusing on promotion of ecological purchasing around the world. IGPN develops internationally harmonised principles of green purchasing, tools for product evaluation, constructs a database of eco-services and products, a database of environmental directives and regulations, training tools, and measurement assessment methods. The objective of IGPN is to spread the green purchasing activities globally to establish ecological supplier networks, which shall contribute to establishment of a sustainable society. 


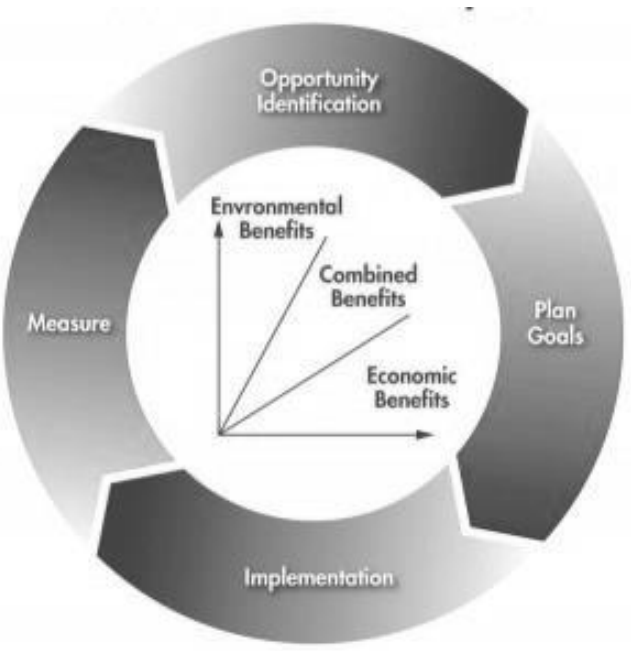

Fig. 2. Simple management model for implementation of GPP

\section{Product policy and environmental tools of its implementation}

Environmentally oriented product policy is in general determined by the relationships between its aims - subjects objects - tools. It is based on the integrated approach to the product life cycle, which anticipates an enormous amount of information. It has to solve the questions of the international trade as well as the rules of the International Trade Organization. New forms of preventive environmental strategies and especially Green Marketing are being introduced helping to solve environmental problems and environmental motivation of producers. Many producers are faced with great attention of the public to their approach to the environment. Despite the fact that the customers buy products fairly prudently and their behaviour is markedly affected by prices, a particular part of the population prefers product that do not burden the environment. This brings about a situation, in which the producers within their mutual competition and in relation to customers are enforced to behave responsibly.

Product policy means analysis, planning, implementation and control of activities (measures, decisions) related to the product as a marketing tool, for instance the external design of a product, composition of a product series, brand policy etc. It is part of a marketing mix. It is closely related to the quality policy. Strategic considerations within the product policy of a company in a competitive environment are dominated by structural and company factors which determine the competition. Success of a company is nowadays based on the philosophy of preparation of products and their launch onto the market where they satisfy needs, wishes and requirements of consumers, or they themselves create these needs, and on the business philosophy based on searching of customers for the existing products offered on the market. Strategic decision-making of businesses in conditions of competition and market globalisation requires knowledge of markets, orientation on the quality, cost reduction and innovations. Understanding of these processes requires obtaining knowledge and being able to apply it in a creative way. The product and its three levels are the basis of the marketing mix and a means to achieve profit from a long-term perspective. The theory on the product and quality can be partially divided into two areas as regards the subject they examine:

- a general theory of product examining the product in all its various forms as regards the requirements and possibilities of its origin, its efficient value, usefulness, quality, processes, activities and their outcomes,

- a specially-focused theory of product examining individual groups of products, internally differentiated or interlinked to individual elements of processes and activities of market entities and the value chain of an entrepreneur company. [5]

The product policy means, in particular, the following 4 areas of interest:

- development and launch of new products on the market

- adaptation of the offered quantity of products to the real needs (based on monitoring the frequency of needs)

- the so-called "product production" (adaptation of technical features, design etc. according to the customer requirements and needs)

- monitoring of the life span of products. [11]

Instruments of the product policy can be applied at the level of the government product policy or the so-called product management which expresses the social responsibility of businesses, consumers and the state.[11]

A company has to define what sustainability means for its business (from the environmental, economic, social as well as ethical point of view) because its approach to the product issues will depend on its vision, obligations and type of business, i.e. the area of products or services.[3] 
Instruments of the product policy can include taxes and subsidies supported by a legal regulation:

- price ones supported by a legal regulation

- economic and regulatory ones supported by a legal regulation

- public procurement supported by a legal regulation

- distribution ones (consumption, logistics)

- communication ones

- technical normalisation

- voluntary (standardised, non-standardised).

There are tendencies in the environmental product policy to extend indirect instruments based to a rather great degree on voluntary activities of producers and a growing environmental awareness of people. Systems of environmental assessment and labelling are implemented to declare that a product meets the parameters complying with the current knowledge, minimises or even eliminates adverse effects on the environment. There is also an effort to assess the product throughout its whole life cycle, i.e. from raw material, through its production, up to its disposal or recycling. Application of these systems results not only from the effort and requirements of state environmental bodies but also from the interest of producers themselves and the consumers.

Labelling of products that are less pollutant for the environment by a state-guaranteed environmental label is a respected and motivating indirect instrument of the product policy. Consumers are thus provided with guaranteed information on the products, the use of which contributes to the environment protection. [6] "Ecolabelling" is a voluntary method of environmental performance certification and labelling that is practised around the world. An "ecolabel" is a label which identifies overall, proven environmental preference of a product or service within a specific product/service category. There are different classifications of label. In contrast to "green" symbols, or claim statements developed by manufacturers and service providers, the most credible labels are based on life cycle considerations; they are awarded by an impartial third-party in relation to certain products or services that are independently determined to meet transparent environmental leadership criteria. Environmental labelling exists as standardised or without any voluntary or obligatory regulation. It is a natural manifestation or product of at least two significant interest groups - a part of producers or businessmen who want to increase the competitive features of their products through qualified labelling on one hand, and a part of consumers, involved environmental activists, researchers and state officers who want to provide or ensure an option to a common as well as industrial consumer to choose those products from the products on the market that have more reliable environmental characteristics.[12]

The LCA (Life-Cycle Assessment) method is one of the most important information tools for environmental policy. It is used for determining adverse environmental impacts of any system (product or service). Information that is provided by the LCA method enables both experts in eco-design and enterprise marketing to select new products and employees of the state administration and in the area of Eco labelling to stipulate regulations and criteria for the support of environmentally friendly products. Last but not least, this information is significant for further scientific and technical development as it realise the causes of harmful effects on the environment. The LCA method can then be summarily defined (according to ISO 14040) as: compilation and evaluation of the inputs, outputs and the potential environmental impacts of a product system throughout its life-cycle. It should be emphasized that the concept of a ,product life-cycle“ is not identical with the concept of the ,service life of a product“. The service life of a product is the period during which a product can be used for the purpose for which it was manufactured and thus constitutes only a small part of the lifecycle of a product.

The eco-design is a systematic process of design and development of a product, that apart from the classic properties as a functionality, economically, security, ergonomically, technical feasibility, aesthetically, a so one, accentuates on the achievement of minimal negative impact of a product on the environment namely in term of whole life cycle. The estimate of the environmental profile of a product has a significant role, it's a specification of all significant factors, by which the product affects on the environment during its whole life cycle. The eco-design is one of the important prevention oriented voluntary regulative tools of the environmental policy.

The preventive bearing of the eco-design is given by that the request for the release of negative impact of a product on the environment is integrated already to the product reflections beginning, so it's going on the most preventive and in term of the practise the most economic approach to the release of negative impacts of products on the environment.

\section{Conclusions}

From the analysis of different ways of the environmental protection in 80's of the last century arose that the most effective and the most economic ways of the environmental protection are based on prevention, then a research and a liquidation of causes, which evocate the contamination of the environment. The application of this preventive strategy for the production processes conduced to the formation of the cleaner production. Over the past decades the European Union has put in place a broad range of environmental legislation. As a result, air, water and soil pollution has significantly been reduced. Chemicals legislation has been modernised and the use of many toxic or hazardous substances has been restricted. However, many challenges persist and these must be tackled together in a structured way. 
Successive environment action programmes have provided the framework for Union action in the field of the environment since 1973. Suitable business and industrial policy and its practical implementation which makes use of more efficient production procedures, applies preventive strategies, uses cleaner technologies and processes in the whole life-cycle of a product and thus reduces generation of wastes, can help reduce the negative impact on the resources and the environment. A positive approach of business and industry to sustainable development can be increased by economic tools such as free-market mechanisms which allow for the product and service prices to reflect the environmental costs of their inputs, production, use, recycling and final disposal in a growing degree and in compliance with the specific conditions in individual countries.

Directions of further work in the field of research task will to Increase of environmental consciousness level among students to study the realities of the work of company (carrying out of audits within the confines of tutorials), starting the project, which could be a collaboration between university and industry in the field of environmental protection and also could help to solve ecological problems worrying Slovak companies. The main focus of next research will be oriented too on two factors determine the success of labelling systems: one is the awareness of consumers and their ability to understand their message, and the other one is the business community's willingness to accept the systems.

\section{Acknowledgements}

This paper was written in frame of the work on the project VEGA 1/0990/15 The readiness of industrial enterprises to implement the requirements of standards for quality management systems ISO 9001:2015 and environmental management systems ISO 14001: 2014 and project KEGA 048TUKE-4/2015Transfer of knowledge from scientific research activities into multimedia education process in the subject "Environment and manufacturing".

\section{References}

[1] Decision No. 1386/2013/EU o General Union Environment Action Program to 2020 „Living well, within the limits of our planet“. Available from: http://eur-lex.europa.eu/legal-content/EN/TXT/?uri=celex\% 3A32013D1386. Accessed: 2017-02-04

[2] Environment Action Program to 2020. Available from: http://ec.europa.eu/environment/action-programme/ Accessed: 2015-03-07

[3] Charter, M. (2001) Ecodesign management. Environmental marking. 2, 3., Prague, pp. 9-11, ISSN $1212-476$

[4] Klinda, J.(1996) Agenda 21 and sustainable indicators. Bratislava, 517 p., ISBN 80-88833-03-5

[5] Kollar, V. et al. (2003) Product policy. Bratislava: Sprint VFRA, 560 p. ISBN 80-88848-96-2

[6] Sustainable Purchasing Available from: http://oxmansafety.com/green_hotels/sustainable_purchasing/ Accessed: 2015-07-09

[7] Nuij R.(2001) Eco-innovation: Helped or hindered by Integrated Product Policy. The Journal of Sustainable Product Design, Vol. 1(1). pp 49-51. ISSN: 1367-6679

[8] Prochazkova, D. ; Wessely, E. ; Rusko, M. \& Kralikova, R. (2011) Human System Safety Management and Environmental Management Relation. In DAAAM International Scientific Book. Chapter 09 in DAAAM . pp.103118. ISSN 1726-9687.

[9] Rubik, F.; Petschow, U. \& Scholl, G.(1995) Basic outline the environmental oriented product policy. Workshop: Instruments of the Product Oriented Environmental Policy of the Middle and Eastern European Countries 20.22.11.1995, Warsaw. Heidelberg/Berlin: IÖW, p. 13

[10] Rusko, M. \& Kralikova, R. (2012) Implementation of environmental management systems in the Slovak enterprises. In: DAAAM International Scientific Book 2012. Vol. 11, no. 31 (2012), p. 369-378. ISSN 1726-9687.

[11] Rusko, M.; Kralikova, R.; Mikulova, M. \& Ilko, J. (2016) Labeling of Products from the Context of Environment, Quality and Safety, Chapter 37 in DAAAM International Scientific Book 2016, pp.419-434, B. Katalinic (Ed.), ISSN 1726-9687, Vienna, Austria. DOI: 10.2507/daaam.scibook.2016.37

[12] Suchanek, Z.(1998) ISO standards for environmental labeling - an effective environmental management tool or a conflicting topic ? In RUSKO,M.[Ed.] Environmental management (EMS, EMAS), Banska Bystrica.1998

[13] Tresnak, P.(2001) 6th EU Environment Action Program. In: Environmental aspects of business, Prague, pp. 4. 